\section{On the verge of Poland's fifth wave of covid-19, healthcare staff are overworked and disenchanted}

\author{
Poland was still struggling under the impact of the Delta variant, which led to a breakdown of the \\ national healthcare system in several regions, when Omicron came knocking on its doors, writes \\ Bartosz Fiałek
}

\section{Bartosz Fiatek rheumatologist}

With only about $56 \%$ of its population fully vaccinated against covid-19 and with the booster dose having been administered to merely a quarter of people, Poland has one of the lowest vaccination coverage among EU countries. ${ }^{1}$ This poor uptake of the vaccine, particularly the booster, paints a rather dim picture for the future of the country, with the highly virulent and worryingly immunity evading Omicron variant knocking on Poland's healthcare doors. It prevents the construction of a nationwide immunity wall, which would otherwise ensure a certain level of stability for Poland's healthcare system, in the form of a lower number of people being hospitalised with severe disease.

Another predicament Poland has to handle is its insufficient number of medical personnel. Poland has one of the lowest ratios of doctors and nurses (2.4 and 5.2, respectively) per 1000 members of the population of all the OECD countries. ${ }^{2}$ Even without the threat of a pandemic, these low staffing numbers pose a challenge to Poland's national healthcare system, but now with covid-19 it has been truly pushed beyond its capacity. Since the number of patients being hospitalised with covid-19 has been steadily increasing, numerous hospitals and health clinics have been unable to handle their other patients or perform their regular services, treatments, and procedures.

Having worked on the emergency wards during the second and fourth waves of covid-19 in Poland, I've had firsthand experience of how our hospitals have struggled to cope, and know that already back in those waves we were not prepared to keep the virus at bay. With an insufficient number of beds in the so-called covid wards, many severely ill covid-19 patients had to remain in intensive care units, which, in turn, prevented other patients who were unwell with various acute or chronic conditions from being admitted. This translated into many preventable deaths. Unfortunately, the Omicron variant is likely to only worsen the situation.

Despite Poland's access to covid-19 vaccines, the government has mounted a poor information campaign about the importance of being vaccinated. We know that the covid-19 vaccines are highly effective at reducing the risk of severe disease, hospitalisation, and death, yet still Polish citizens have been reluctant in reaching for what life saving science has to offer.

To me, witnessing the daily reality within our limping Polish healthcare system, taken together with the low proportion of our population who are fully vaccinated, and the widespread reluctance of Polish people to follow infection prevention and control measures, doesn't leave me hopeful for this country's encounter with Omicron.

This week, Poland continued to hit new records in its daily case numbers ${ }^{3}: 53420$ new infections were reported on 26 January, with Omicron estimated to account for $40 \%$ of these. ${ }^{4}$ The steadily skyrocketing number of covid-19 cases in Poland will inevitably, though with a slight delay, translate to an increased number of people being hospitalised and possibly deaths. Polish hospitals and clinics will be severely stretched to maintain the continuity of diagnostic and therapeutic services, particularly in already overloaded units, and indeed seem doomed to fail. Where Polish authorities try to fix these problems, they often seem to create more. For example, the government announced last week that they would be increasing the number of hospital beds for covid-19 patients and that any patient over the age of 60 who tests positive for covid-19 will now be seen by a GP. These measures aim to ensure that patients with covid-19 are still cared for by Poland's healthcare infrastructure, but amid an already understaffed and barely effective healthcare system, they seem likely to deprive even more non-covid-19 patients of the care they need. ${ }^{5}$

Polish national healthcare looks likely to be facing yet another crisis imminently, yet the government continues to follow a strategy that fails to prevent and control the Omicron variant. Worse still, senior members of the government have continued to downplay the risks from covid-19, with health minister Adam Niedzielski saying at the start of January that the rise in infections during January was an "anomaly." 6 As the government fails to be guided by the science, it's no wonder that 13 out of 17 members of the medical board that advises the prime minister recently resigned. ${ }^{7}$

The majority of healthcare workers are overworked and disenchanted with the ongoing paucities in the system. According to a questionnaire carried out by one of Poland's national universities, around $15 \%$ of doctors and $10 \%$ of nurses are considering quitting their jobs once the pandemic is over. ${ }^{8}$ To make matters worse, we not only need to contend with chronic shortages in the system, but also the continuous wave of hostility that medical personnel have been subjected to by parts of Polish society. 
I strongly think that only by making bold decisions will we be able to prevent a national healthcare crisis brought about by the Omicron variant. Firstly, the government should focus on clear and consistent messaging to promote covid vaccination and dispel misinformation, not ruling out vaccine mandates for certain key groups. Secondly, non-pharmaceutical interventions, such as wearing masks in enclosed spaces, should be properly enforced, with those ignoring the rule subject to fines unless exempt. Finally, only those who have been fully vaccinated should be allowed to enter public venues, as is the case in many other European countries.

I know that such measures can seem a nuisance, however, we've seen how they have been successfully implemented by several European countries. These measures could help to bring our already overloaded healthcare system back from the brink. It is never too late to introduce these interventions. After all, the stakes are high: the health and life of Polish people.

Competing interests: regional head of the OZZL doctors' union in Poland. Nothing further declared.

Provenance and peer review: commissioned; not peer reviewed.

1 COVID-19 in Europe. Record daily cases in Russia, Poland, and Romania. Euronews. 22 January 2022. https://www.euronews.com/2022/01/19/covid-19-in-europe-record-case-numbers-infrance-and-germany-as-omicron-spreads

2 OECD/European Observatory on Health Systems and Policies. (2017), Poland: Country Health Profile 2017, State of Health in the EU. OECD Publishing, Paris/European Observatory on Health Systems and Policies, Brussels. doi: 10.1787/9789264283510-en

3 Chao-Fong L, Otte J. Japan and Poland log record cases; Germany seven-day rate at new high as it happened. The Guardian. 23 January 2022. https://www.the-

guardian.com/world/live/2022/jan/22/coronavirus-live-japan-and-taiwan-report-omicron-surgesireland-lifts-restrictions

4 Poland hits COVID case record, as Eastern Europe battles surge. Reuters. 26 January 2022. https://www.reuters.com/world/europe/poland-report-over-50000-covid-cases-wednesdayofficial-says-2022-01-26/

5 Koschalka B. Poland to offer free Covid tests in pharmacies and shorten quarantine amid Omicron surge. Notes from Poland. 21 January 2022. https://notesfrompoland.com/2022/01/21/polandto-offer-free-covid-tests-in-pharmacies-and-shorten-quarantine-amid-omicron-surge/

6 Kość W. Majority of Polish medical panel quits in protest at government inaction on COVID. Politico. 14 January 2022. https://www.politico.eu/article/poland-medical-panel-quits-protestgovernment-inaction-coronavirus/.

7 Dyer O. Covid-19: Poland's medical council sees mass resignations over government inaction on pandemic. BM/2022;376:0137. https://www.bmj.com/content/376/bmj.0137. doi: 10.1136/bmj.0137 pmid: 35042685

8 Report: after the pandemic, 15 per cent of doctors intend to leave the labour market [Polish]. Raport: po pandemii 15 proc. lekarzy zamierza odejść z rynku pracy. Puls Medycyny. 22 October 2020. https://pulsmedycyny.pl/raport-po-pandemii-15-proc-lekarzy-zamierza-odejsc-z-rynkupracy-1006274 